Revista Ibero-Americana de Ciências Ambientais

Ibero-American Journal of Environmental Science

Out, Nov, Dez 2016, Jan 2017 - v.8 - n.2

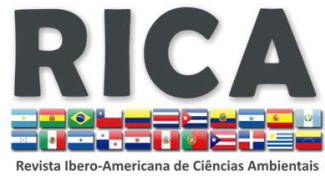

ISSN: 2179-6858
SUSTENERE

Publishing Corporation
This article is also available online at: www.sustenere.co/journals

\title{
Economia e opções energéticas
}

A economia globalizada condiciona cada vez mais em volume e intensidade, a exploração dos energéticos de base fóssil e não só notadamente petróleo, gás natural e eletricidade. Isto acarreta impactos sobre o meio ambiente, de modo a pôr em xeque parte significativa dos esforços voltados para o delineamento, promoção e execução de modelos mais sustentáveis em termos de crescimento e desenvolvimento socioeconômico. A ordem do sistema global, bem como suas implicações de modo econômico, geopolítico e geoestratégico, impõe escolhas equivocadas em termos energéticos, e também restrições aos países detentores dos recursos naturais, definindo modelos intensos com relação à exploração dos mesmos, fruto da inserção dos países em desenvolvimento no processo da globalizada de mercados, de modo a provocar consequências a nível do meio ambiente e do próprio modelo de desenvolvimento desses países, com impactos extremamente adversos em termos socioambientais.

Palavras-chave: Ordem Global; Recursos Energéticos; Meio Ambiente.

\section{Economy and energy options}

The globalized economy increasingly conditions in volume and intensity, the exploitation of fossil-based energy and not only oil, natural gas and electricity. This has impacts on the environment, in order to call into question a significant part of the efforts aimed at designing, promoting and implementing more sustainable models in terms of growth and socioeconomic development. The order of the global system, as well as its implications in an economic, geopolitical and geostrategic manner, imposes misguided choices in energy terms, as well as restrictions on natural resource countries, defining intense models regarding their exploitation, as a result of the insertion of countries in the process of globalization of markets, in order to have consequences for the environment and the very development model of these countries, with extremely adverse impacts in socio-environmental terms.

Keywords: Global Order; Energy Resources; Environment.

Topic: Educação Ambiental

Reviewed anonymously in the process of blind peer.

Manoel Gonçalves Rodrigues

Universidade Federal do Rio de Janeiro, Brasil.

http://lattes.cnpq.br/5940113046592928

manoel.rodrigues@terra.com.br

Fernando José Pereira da Costa

Universidade de Santiago de Compostela, Espanha.

http://lattes.cnpq.br/0908286687921354

fjpcosta@sapo.pt
Received: 05/10/2016

Approved: 23/01/2017

\section{Referencing this:}

RODRIGUES, M. G.; COSTA, F. J. P.. Economia e opções energéticas. Revista Ibero-Americana de Ciências Ambientais, v.8, n.2, p.289-298, 2017. DOI: http://doi.org/10.6008/SPC2179-6858.2017.002.0023 


\section{INTRODUÇÃO}

No contexto da economia capitalista sistema-mundo, registra-se a configuração de modelos econômicos, produtivos e energéticos de cariz perdulário, desperdiçador e irracional, fruto de um modelo definido por uma inserção subordinada dos em desenvolvimento no âmbito da economia mundial. Esta, por seu lado, manifesta-se a nível da Divisão Internacional do Trabalho (DIT), também referida como Divisão Internacional do Trabalho e da Produção (DITP).

Efetivamente, a DIT/DITP, a envolver assimetrias do ponto de vista industrial e tecnológico, delineia, por assim dizer, um roteiro quanto ao papel a desempenhar, quer pelas nações do subsistema em desenvolvimento quer pelos países orgânico-centrais do capitalismo-mundo. Se a estes últimos caberiam posições cimeiras em termos produtivos e tecnológicos, aos outros imputam-se posições bem mais modestas em termos do aparato industrial e da base tecnológica.

Enquanto os países orgânico-centrais centram-se na elaboração de bens dotados de elevada complexidade tecnológica, às economias em desenvolvimento destina-se a produção de bens de limitado nível de incorporação tecnológica, e ainda que industrializados, matérias primas agrícolas, minerais e energéticas.

\section{DISCUSSÃO TEÓRICA}

\section{Energia e Economia Global}

Os países em desenvolvimento mostram uma situação estruturalmente deficitária a nível do balanço de pagamentos, fruto de restrições produtivas e tecnológicas, do elevado grau de inelasticidade das importações especialmente de bens e serviços de natureza tecnológica, como é o caso dos bens de capital. O déficit estrutural do balanço de pagamentos das nações em desenvolvimento aparece mais claramente demonstrado na situação a descoberto do saldo da balança comercial delas. Desse modo, a análise estruturalista mostra que existe uma defasagem entre os países em desenvolvimento e os orgânico-centrais no que se refere aos termos de troca entre eles na esfera do comércio internacional. A nível econômico, um bem industrializado com elevado grau de incorporação tecnológica acrescenta muito mais valor do que recursos energéticos exportados sem qualquer ou reduzido beneficiamento.

A rigidez se verifica quer a nível da pauta de importações (por exemplo: máquinas, equipamentos, processos, serviços de engenharia e consultoria tecnológica), quer do conjunto das exportações (a destacar: bens primários, commodities várias - agrícolas, pecuárias e minerais -, bens beneficiados de baixo valor acrescentado, produtos industrializados de baixo/médio nível de sofisticação e incorporação tecnológica). Na senda de Porcile et al. (2002) e de Prebisch (1986), esses desequilíbrios (marcantes na balança comercial) explicar-se-iam pela desigual difusão do progresso técnico a nível mundial, que conduz a assimetrias tecnológicas entre os países e que se traduzem por diferenciais internacionais de competitividade. Assim sendo, os países orgânico-centrais do capitalismo-mundo mostrariam economias maduras, integradas, fruto de processos de industrialização completos a dispor de capital e tecnologia, enquanto os países 
periféricos/semiperiféricos concentram suas atividades no setor primário ou em segmentos industriais (ou semi-industriais) de baixo valor acrescentado. Por outro lado, como a elasticidade-renda dos produtos industrializados (de máquinas e equipamentos, por exemplo) é bem maior do que as dos produtos primários ou industrializados de baixo nível de complexidade, os termos de troca mostram-se sempre adversos para as economias em desenvolvimento.

O gap de competitividade existente entre os países orgânico-centrais e os periféricos/semiperiféricos explica a deterioração crescente das trocas externas em detrimento desses últimos, fruto dos diferentes graus de complexidade produtivo-tecnológica a caracterizar um e outro desses distintos blocos. De fato, centrar a produção em bens primários (recursos energéticos aí incluídos), em bens industrializados de baixo ou médio grau de sofisticação a nível da sua elaboração e limitado cariz tecnológico (beneficiamento de minerais ou a transformação de bens intensivos em energia mas de baixo valor acrescentado) em muito difere da aposta em bens de vanguarda, a se constituírem na ponta de lança da inovação/tecnologia. A diferença é abissal quanto aos resultados de uma e outra categoria, com as atividades geradoras de menor valor acrescentado conduzindo a intensos consumos de energia e a impactos perversos sobre o meio ambiente, uma vez que o elevado valor assumido pelo ratio «Energia/VAB» a implicar, muitas vezes, na maximização do binômio «Energia/PIB», conduz a resultados pouco auspiciosos em termos da relação «Energia/Meio Ambiente».

No caso de inúmeros países em desenvolvimento, é normal o recurso à base de recursos naturais e energéticos como instrumento de um processo modernizador deles. Entretanto, os impactos adversos a nível do consumo de energia e de impactos (in)diretos sobre o meio ambiente, muitas vezes mais do que anulam os aparentes ganhos de natureza econômica. Do ponto de vista de um efetivo processo de desenvolvimento, os projetos industriais intensivos em energia, em particular de eletricidade, destinam-se ao aproveitamento simultâneo de abundantes bases de recursos minerais e energéticos.

\section{Opção Gasotérmica e Subordinação Global}

Ao recorrer a Almeida (2013); Costa (2004) e Lessa (2007), assinala-se que o aproveitamento energético e econômico do gás natural, da mesma forma que no caso dos demais combustíveis fósseis, em razão do seu caráter de energético não renovável, implica em grandes interesses, acirradas disputas e acesos conflitos, num ambiente externo de cunho muito mais de confronto do que de cooperação a nível interestatal. De fato, existe, a nível do cenário petrolífero/gasífero mundial, um ambiente externo de cunho muito mais de confronto do que de complementação a nível interestatal, visto ser extremamente difícil a convergência de interesses entre estados produtores e consumidores que conduzam à efetivação de acordos geopolíticos/geoeconômicos, o que se agrava com a comoditização do gás natural, de modo a seguir o padrão da financeirização da riqueza. A comoditização do gás natural, no contexto do processo de formação de um mercado mundial desse combustível, seria de interesse das grandes empresas petrolíferas internacionais, uma vez que as manteriam no processo e de forma dominante. 
Com relação à financeirização da riqueza cabe assinalar que a liberalização dos mercados financeiros, iniciada nos Estados Unidos da América em meados dos anos 1980 e a desregulamentação das taxas de juros promovida pelo Federal Reserve (FED) e por seus congêneres europeus, as quais seguiu-se a valorização do yen, conduziram a grandes mudanças nos mercados de capitais e financeiros. Nos países em desenvolvimento, as economias defrontam-se com desequilíbrios dos balanços de pagamentos, já comprometidos pelos choques petrolíferos dos anos 1970 e pela recessão mundial, situação em muito agravada pelo aumento das taxas de juros internacionais provocado pelo hegemon estado-unidense. 0 domínio absoluto da lógica financeira impõe-se sobre a economia mundial, de forma mais nítida a partir da década de oitenta, sendo impulsionado pela hegemonia do dólar flexível. Isto marca o limite das estratégias desenvolvimentistas, cujo financiamento calcava-se no endividamento externo e a incontestável vitória da revanche liberal-conservadora, marcando o triunfo do neoliberalismo como modelo dominante.

Relativamente à relação entre gás natural e geração termelétrica, serão Santos et al (2007) a observar que um segmento de grande relevância para a demanda de gás natural, mormente a nível dos países orgânico-centrais, diz respeito à sua utilização em centrais termelétricas (geração de energia elétrica). As termelétricas a gás natural possuem um baixo custo de construção das instalações comparativamente a unidades geradoras que se valem de outras fontes de energia (carvão, óleo combustível, óleo diesel, hídrica e nuclear), e apresentam uma tecnologia de geração de significativa eficiência. Em razão disso, torna-se exequível o estabelecimento de contratos bilaterais de longo prazo entre as geradoras e os consumidores notadamente a indústria, em especial os de grande porte. A geração termelétrica a gás natural mostra-se relativamente menos poluente do que a oriunda de outros combustíveis fósseis e/ou derivados (carvão, óleo diesel e óleo combustível) e face à opção hidrelétrica apresenta nítidas vantagens, a saber: prazo menos dilatado de retorno do investimento, principalmente face à opção hidrelétrica; possibilidade de obtenção de ganhos energéticos a nível dos usos finais/intermédios, principalmente na indústria, e elevado potencial em termos de sofisticação e difusão tecnológica.

Por outro lado, consoante o avançado por Lima et al (2010), a modalidade de geração termelétrica a gás natural mostra ainda uma série de pontos a seu favor (pequenos volumes de investimentos, reduzido prazo de construção, possibilidade de construção das usinas próximas aos centros de carga, geração de empregos no local, estimulo a investimentos para a região, pequenas áreas ocupadas, flexibilidade operacional, etc.). No caso de um país com base de geração elétrica estruturalmente/predominantemente hídrica, as unidades termelétricas a gás natural apresentam a possibilidade de trabalhar apenas nos horários de ponta ou em períodos de forte demanda e ocorrência de picos de consumo ou ainda em épocas de estiagem prolongada com a baixa significativa dos níveis dos reservatórios, de modo a assegurar a energia firme para o atendimento do consumo, não se condicionando a restrições de ordem climática, mas antes ao abastecimento/fornecimento do próprio gás natural. Assim sendo, para além do fato do gás natural se constituir num combustível fóssil, logo poluente embora menos face ao carvão e petróleo, e finito, há também a considerar, como aspectos limitativos à sua utilização na produção de energia elétrica, a sua disponibilidade, uma vez haver riscos quanto ao seu suprimento. 
Por outro lado, a nível da geração térmica de eletricidade, o gás natural mostra-se competitivo no que diz respeito aos derivados de petróleo, na faixa de US\$27,00 por MWh para o gás natural em relação à média de US\$ 105 por MWh para o óleo (Matias, 2007). As suas vantagens face to face as alternativas com relação à geração eletrotérmica não se ficariam apenas nos benefícios com relação a menores impactos ambientais por exemplo nas emissões de $\mathrm{CO} 2$, ou nos auspiciosos caminhos abertos ao progresso tecnológico e à inovação, mas também no âmbito dos custos afetos à sua utilização enquanto combustível. Conforme é mostrado no quadro acima, montado em cima da realidade brasileira da segunda metade do primeiro decênio dos anos 2000, o custo do MWh termelétrico gerado com a utilização do gás natural em pouco supera a quarta parte do obtido mediante o recurso aos petro derivados especialmente o óleo combustível, ficando pouco acima do conseguido através da utilização do carvão.

De acordo com Aneel (2005), a geração de energia elétrica a valer-se do gás natural dá-se através da queima desse combustível em turbinas a gás. A turbina a gás é o equipamento-chave para a geração térmica e que uma vez acoplada a um gerador (turbo gerador) transforma a energia contida no gás natural em potência mecânica, por sua vez convertendo-a através de um gerador em energia elétrica. A geração termelétrica a gás natural tem ainda como vantagens o prazo relativamente curto de maturação do empreendimento e a flexibilidade para o atendimento de cargas de ponta. Estão relacionadas ao pico de demanda/consumo de energia elétrica, que tanto pode se referir a algumas horas do dia (por exemplo: de $17 \mathrm{~h}$ até $21 \mathrm{~h}$ ), quanto à demanda média semanal, mensal etc. Entretanto, as turbinas a gás mostram extrema sensibilidade face às condições climáticas (em especial com relação à temperatura ambiente), para além de apresentarem alterações substanciais de rendimento térmico no caso da operação em cargas parciais.

Já para Almeida (2013) e Santos et al. (2007), o papel do gás natural, enquanto fonte de energia estratégica a nível mundial, mostrou um significativo incremento desde os anos 1980/1990. Essa evolução ocorreria principalmente devido aos menores impactos ambientais acarretados pelo uso do gás natural face aos demais energéticos de base fóssil, petróleo e carvão. De fato, apesar de ser muitas vezes caracterizado como um combustível limpo, o gás natural, na realidade, não pode ser assim considerado de forma integral. De fato, o gás natural é, de um modo geral, menos impactante para o meio ambiente do que o petróleo e o carvão mineral. Desse modo, a título de ilustração, cita-se que o uso do gás natural em equipamentos adequados mostra-se relativamente menos poluente do que a queima de óleo diesel. $\mathrm{O}$ gás natural permite uma combustão com elevado rendimento térmico, assim como controle e regulagem da chama, possibilitando a obtenção de reduções a nível da intensidade do consumo de energia nos segmentos em que é utilizado na indústria, comercio, serviços, residências e transportes.

Consoante o que é destacado por Praça (2003) e Rodrigues \& Guerra (2004), com relação à utilização do gás natural na geração de eletricidade, há que registrar que a partir dos anos 1980 verifica-se uma profunda alteração no que diz respeito ao paradigma tecnológico da geração elétrica mundial, em especial no caso dos países detentores de um reduzido potencial hidrelétrico ou em que o mesmo já se encontrava, na sua maior parte ou mesmo na totalidade, aproveitado. Era esse o quadro nos países orgânico-centrais mais avançados como Estados Unidos da América, Europa Ocidental, Japão e países asiáticos mais 
industrializados, dentre outros. De fato, a geração elétrica nesses países, até essa altura, apresentava uma profunda dependência de centrais nucleares ou termelétricas. A complementar esse quadro havia unidades de geração a gás natural direcionadas ao atendimento das demandas de pico. Em termos efetivos, estas são regiões de quase esgotamento ou inexistência de recursos hídricos a respaldar a geração elétrica. Portanto, nesses casos, a opção gasífera representava uma solução de ponta e relativamente menos emissora do que os demais combustíveis fósseis, para além de não implicar nos riscos afetos ao nuclear.

Na realidade, em razão do que afirmam Rodrigues \& Guerra (2004), seria somente no século XX e principalmente no contexto do mercado estado-unidense que o gás natural despontaria como uma opção clara em termos de disponibilidade/aplicação energética, assumindo aí grande importância enquanto elemento promotor do progresso/desenvolvimento dos Estados Unidos da América a nível socioeconômico. Contudo, em termos de outros países e regiões afetas ao «Núcleo Orgânico Central» do capitalismo-mundo, a entrada do gás natural ocorreria bem mais tarde, principalmente no período posterior à Segunda Guerra Mundial. No caso das economias orgânico-centrais, o consumo de gás natural concentra-se em três grandes mercados, quais sejam: produção de calor/vapor na atividade industrial, geração de eletricidade e setor doméstico (aquecimento e cocção). Em termos dos países integrados ao processo de desenvolvimento do sistema econômico mundial, o interesse pelo gás natural é relativamente recente, aí buscando-se definir o seu grau de penetração em termos da matriz energética, assim como os potenciais usos/mercados. Estes, por seu lado, constituem-se naqueles que se mostram como os mais vantajosos para esse energético, tidos como os mercados mais nobres, a saber: consumo doméstico e setor petroquímico (na verdade, gasoquímico).

Assinala Nunes (2007) que a gaso-eletrogeração cresce, a nível dos países orgânico-centrais, com a simultânea liberalização dos mercados energéticos, bem como com a disponibilidade de gás natural na sua versão liquefeita e o papel a ser desempenhado por ele. Com efeito, no início desse processo, tende a caber à geração a gás o papel nuclear de dar resposta aos picos da procura de eletricidade, enquanto a geraçãobase é assegurada, por alguma(s) alternativa(s) mais adequada(s) e que se afirmaram no quadro de cada caso histórico (nuclear, carvão ou a via hídrica). De fato, os anos 1990, no contexto dos países orgânico-centrais, trariam consigo a plena afirmação do eletro geração a gás natural, que passa a ser hegemônica no primeiro quinquênio do século XXI. Tal se encontra relacionado a aspectos de ordem essencialmente econômica, uma vez que a eletrogasogeração a valer-se da tecnologia de ciclo combinado apresenta maior competitividade do que a alternativa das turbinas a gás de ciclo aberto. 0 padrão energo-fóssil tem limites físicos e meio ambientais, mormente no caso da eletricidade de base carbonífera/petrolífera em processos térmicoindustriais e aquecimento ambiente.

Assim sendo, a entrada em cena do gás natural só faria sentido no contexto do arrefecimento da demanda total de energia, na busca por novos padrões de consumo, no alcance de níveis mais elevados de eficiência energo-produtiva, na diversificação das fontes de energia para a geração de eletricidade e na disponibilização de energia térmica (consequência do avanço tecnológico), uma vez que o padrão energofóssil tem limites (físicos e meio ambientais), mormente no caso da eletricidade de base 
carbonífera/petrolífera em processos térmico-industriais e aquecimento ambiente. Ademais, o gás natural, no contexto dos países orgânico-centrais, faz todo o sentido em razão dos ganhos de eficiência, da economia de energia primária, do grau de modernização/sofisticação dos equipamentos, dos custos e dos menores impactos meio ambientais comparativamente aos energéticos de base fóssil. Desse modo, a nível dos países orgânico-centrais detentores de capital e tecnologia, para além de não possuidores de grande potencial hídrico, o gás natural é a opção correta a adotar, quer a nível energético, que rem termos da geração de eletricidade, quer ainda a nível meio ambiental.

Por outro lado, em razão do que evidenciam Garcez (2007) e Januzzi et al. (1997), o consumo do gás natural, no caso dos países orgânico-centrais do hemisfério norte, tenderia a crescer não apenas pela via da geração termelétrica, mas também a nível de usos intermédios, notadamente no que diz respeito a processos técnico produtivos e térmico-industriais. A termoeletricidade é inerente a inúmeros processos produtivoindustriais e a diversas tecnologias de processo, para além de base energo-motriz a acionar e fazer funcionar máquinas e equipamentos em inúmeras unidades técnico fabris e incontáveis etapas de diversos processos industriais de produção. O fato é que nesses países vale-se da energia fóssil para a produção de eletricidade. O gás natural é o combustível fóssil que tem menos impactos adversos sobre o meio ambiente, gerando menos resíduos/emissões, para além de apresentar outras vantagens de carácter técnico-econômico, energo-industrial e operacional, de modo a ser considerado, por algumas perspectivas, como um clean energy source, que não o é de todo, visto a sua origem fóssil.

Registra Borelli (2005) que no caso do Brasil a intensificação do uso do gás natural associa-se fortemente à geração termelétrica (no caso, gasotérmica), trajetória que na situação de um país a contar com eletro geração de base hídrica remete imediatamente ao custo do quilowatt-hora (Kwh) gerado pela componente gasotermelétrica como condição sine qua non à expansão da capacidade instalada de geração. Coloca-se, portanto, a questão da competitividade da termeletricidade, em particular da variante gasotérmica, daí dependendo a viabilização dos projetos de investimento, a definição de rumos entre a hidreletricidade e a termeletricidade/gaso-eletricidade e mesmo as possibilidades de complementação entre as duas eletro modalidades de geração. A questão da produtividade/competitividade da gasotermeletricidade assume maior relevância quando se registra que o preço do gás natural chega a determinar $60 \%$ do preço final da energia gerada.

O recurso à opção gasífera por parte de um país em desenvolvimento a dispor de um elevado potencial hidráulico subaproveitado, mas a contar com todo um arcabouço tecnológico e toda uma expertise em termos de engenharia e capacidade gestionário-organizativa de base hidrelétrica encontra sérios problemas para se concretizar, pelo menos à larga escala. A verdade é que um sistema elétrico de qualidade deve garantir/assegurar o fornecimento em tempo integral, não se podendo basear única e exclusivamente na base hídrica, devendo recorrer a fontes energéticas armazenáveis ou não - no primeiro caso com combustíveis fósseis carvão, petróleo e urânio; e, no segundo com fontes renováveis (solar, eólica, etc.) -, com o fito de se assegurar a quantidade de energia com que se possa efetivamente contar (energia firme). Um sistema de pilar hídrico irá depender do regime de vazão dos rios, não sendo tecnicamente possível gerar 
a totalidade de energia elétrica na época das cheias, armazená-la e disponibilizá-la para consumo nas épocas de estiagem, uma vez que a geração e o consumo de energia elétrica ocorrem no mesmo instante, muito embora se possa ampliar o nível de energia potencial a partir da não utilização total ou parcial da fonte primária.

Parte-se das pistas abertas por considerações de Zoratto (2002) para assinalar que a termoeletricidade gasífera implica numa forte dependência da grande maioria dos países periféricos/semiperiféricos, ainda que possuidores de reservas a níveis bastante consideráveis. $O$ fato é que a opção gasotérmica apresenta um forte cariz tecnologista, ou seja, com unidades geradoras a contar com um elevado nível de incorporação tecnológica e atuando como difusoras de tecnologia em termos de processos/equipamentos. Tais plantas são praticamente importadas na sua totalidade, mesmo porque o baixo nível de penetração do gás natural nas sociedades periféricas/semiperiféricas não possibilita a obtenção de ganhos de escala que viessem a estimular a fixação local das empresas produtoras de equipamentos, no que se poderia vir a constituir num virtuoso processo substituidor de importações. Portanto, que traz implícita uma forte dependência de carácter tecnológico em termos da instalação, operação, funcionamento e reparo das plantas térmico-gasíferas no âmbito da Periferia/Semiperiferia. Nestes casos, optar pelo gás natural conduz a perdas pelo lado da balança comercial (importações de equipamentos, peças de reposição e mesmo de gás natural), bem como da balança de serviços.

No caso de um país em desenvolvimento, a geração termelétrica a gás natural implica em fortes condicionantes de raiz tecnológica, que lhe podem acirrar o nível de dependência nessa área, já em si bastante elevado. O problema torna-se bem mais grave quando esse país é detentor de um enorme potencial hídrico ainda subutilizado, embora mantenha um significativo volume em termos de hidro geração. A capacitação e a base tecnológica advêm da utilização da base hídrica e pode vir a se constituir em elemento de dinamização industrial/tecnológica quanto à gasogeração destinada a suprir a ponta do sistema. A ampliação e reforço da hidro geração poderia implicar num processo de aprendizagem a desembocar na gasogeração, na produção interna de equipamentos gasíferos e na criação de escala produtivo-tecnológica. Em outras palavras, num contexto como esse, o gás natural poderia ser usado para firmar a energia elétrica produzida pelo sistema. Para além disso, no universo das termelétricas movidas a combustíveis fósseis, as centrais a gás natural são bem menos poluentes do que as usinas a carvão ou a óleo, emitindo menos $\mathrm{CO} 2 \mathrm{e}$ com impactos menos agressivos sobre o meio ambiente. Como desvantagem tem-se o fato de que a energia elétrica pode ser gerada a partir de outras fontes que não as fósseis de um modo geral e o gás natural em particular em solar, eólica, biomassa etc.

Por outro lado, o gás natural tem usos mais nobres do que a queima numa termelétrica, notadamente na produção industrial, na qual se mostra como modernizador de equipamentos, processos e produtos, vindo a se constituir em elemento de ponta na promoção e difusão do progresso tecnológico. Com isso, não se perderia a oportunidade de se ter o gás natural como recurso energo-industrial e fomentador/viabilizador de uma indústria nacional de equipamentos industriais de ponta. Por outro lado, a decisão mais difícil parece residir na opção eletrogasífera. Esta, a ser implementada, o deveria ser somente 
a nível da ponta do sistema. Os projetos eletrogasíferos são caros, exigem vultosos investimentos e elevados níveis de capitais embora com prazos de maturação menos largos do que as hidrelétricas, para além de um alto nível de importações em termos de equipamentos e tecnologia, o que acaba por onerar o balanço de pagamentos, principalmente pelo lado da balança comercial. Os investimentos dos grandes fabricantes transnacionais de equipamentos só entrariam uma vez criadas as escalas mínimas necessárias.

Contudo, num país de base hídrica claramente subutilizada (o caso nítido do Brasil) e a contar com uma multiplicidade de possibilidades em termos de geração térmica, a hipótese da gasogeração elétrica (na base) deveria ser mais bem pensada/refletida mesmo para um horizonte de longo ou muito longo prazo. De fato, a longo prazo ou a muito longo prazo, uma vez efetivamente esgotados os imensos e subaproveitados recursos hídricos, o País não deve descartar a opção gasotérmica de início adotando-a para firmar a ponta, mas deve preparar-se para tal, em termos industriais, produtivos e tecnológicos. Assim sendo, a termogasogeração, no caso de um país a contar com as características do Brasil predominante e subaproveitamento hídrico, e só deveria considerar a opção gasotérmica, num primeiro momento e durante ainda muitos anos, para firmar a ponta do sistema elétrico, modernizando o parque eletrotérmico existente e substituindo as térmicas a operar à base dos combustíveis fósseis convencionais, de modo a torná-las menos poluentes e a reduzir as emissões de $\mathrm{CO} 2$ e outras substâncias.

Por outro lado, haveria que pensar no uso industrial do gás natural, a substituir o óleo combustível, quiçá a eletricidade, e, a abastecer novas unidades industriais a entrar em funcionamento e em que a alternativa energogasífera mostre nítidas vantagens. A partir daí, o gás natural poderá vir a se constituir em combustível importante a nível do auto geração e da cogeração. No entanto, seria quanto à eletro geração que o gás natural poderia realizar a parcela maior do seu potencial energético. Contudo, seria primeiro de se fazer cumprir o potencial eletro hídrico ainda não aproveitado para depois se pensar na expansão planejada da gasogeração elétrica. Mas o aspecto mais importante esteja talvez ligado à instalação de um parque industrial direcionado à produção de equipamentos para o aproveitamento energético do gás natural. Esta se daria em termos da produção, transporte e distribuição. Entretanto, seria a nível do eletro geração (na base) que se concentraria o principal mercado, o que seria incoerente face ao universo de recursos energéticos efetivo e potencial existente no País.

\section{CONSIDERAÇÕES FINAIS}

A entrada do gás natural a nível da matriz energética brasileira é notória e deve crescer. Contudo, questiona-se o açodamento face à geração eletrotérmica, em razão principalmente do elevado potencial de geração hidrelétrica do Brasil, que o utiliza em cerca de 1/4; muito embora não se considere a entrada dos recentes projetos hidrelétricos, principalmente com Belo Monte. Por outro lado, a tecnologia do ciclo combinado é cara e controlada por um pequeno grupo de empresas transnacionais, que aparentemente, pelo menos por enquanto, não mostraram grande interesse de se instalar no Brasil, com toda a sua linha de produção e os respectivos (e desejáveis) linkages com empresas nacionais ou transnacionais que no País 
venham a se instalar peças, partes, componentes e toda a linha de equipamentos, conforme ocorreu com a hidreletricidade.

Há usos mais urgentes para o gás natural nos transportes e comercio/distribuição, e, ele poderia vir a ser um grande energético para o setor industrial, sofisticando produtos, refinando equipamentos, substituindo o óleo combustível, deslocando a eletricidade em processos eletrotérmicos, para além de servir de base a processos de auto geração/cogeração.

A questão de se ter o gás natural como uma fonte de energia efetivamente alternativa apesar de fóssil, ganha relevância com o seu uso termelétrico. Este, por sua vez, implica no recurso a equipamentos com elevado grau de incorporação e complexidade tecnológica em particular a turbina a gás, a exigir níveis por demais altaneiros em termos de capacitação, em geral presentes em grandes empresas transnacionais de base oligopolizada, detentores de um grau de extrema proeminência a nível da concentração de capitais a respaldar os crescentes esforços em Pesquisa e Desenvolvimento (P\&D).

Desse modo, destaca-se que nesse segmento industrial tem-se a inovação e a incorporação de tecnologia como elementos concorrenciais básicos a guiar o processo de acumulação e reprodução de capital. Assim sendo, a questão de se ter o gás natural como fonte energética alternativa, naquilo que se refere à geração eletrotérmica, tem a ver com a possibilidade de se promover o acesso à essa base tecnológica e de se viabilizar o necessário processo de capacitação.

\section{REFERÊNCIAS}

ALMEIDA, A. P.. O Gás Natural como Riqueza Estratégica da América do Sul. In: ENCONTRO NACIONAL DA ASSOCIAÇÃO BRASILEIRA DE RELAÇÕES INTERNACIONAIS, 3. Anais. Belo Horizonte, 2013.

ANEEL. Atlas de Energia Elétrica do Brasil. 2 ed. Brasília: Aneel, 2005.

BORELLI, S. J. S.. Método para a Análise da Composição do Custo da Eletricidade Gerada por Usinas Termelétricas em Ciclo Combinado a Gás Natural. Dissertação (Mestrado) Universidade de São Paulo, São Paulo, 2005.

COSTA, G. M. M.. Telecomunicações e o Poder Global do EUA. In: FIORI, J. L.. O Poder Americano. Petrópolis: Vozes, 2004.

GARCEZ, C. A. G.. Gás Natural: Energia Econômica e Ambientalmente Vantajosa. Dissertação (Mestrado) Universidade de Taubaté, Taubaté, 2007.

JANUZZI, G. M.; SWISHER, J. M. P.. Planejamento Integrado de Recursos Energéticos: Meio Ambiente, Conservação de Energia e Fontes Renováveis. Campinas: 1997.

LESSA, C.. O Brasil à Luz do Apagão. Rio de Janeiro: Razão Cultural, 2001.

LIMA, L. J. B.. Geração de Energia com Gás Natural. Trabalho (Graduação em Engenharia de Petróleo e Gás) - Universidade Estácio de Sá, Macaé, 2010.
MATIAS, S. G.. Análise Comparativa entre os Custos Correspondentes às Usinas Termelétricas Vencedoras do Leilão de Energia Nova Realizado em 16/10/07 e os Custos Previstos para a Usina Nuclear Angra 3. Economia \& Energia, Rio de Janeiro, v.11, n.65, p.36-40, 2007.

NUNES, C. C.. Geoeconomia do Gás Natural e a União Europeia. Lisboa: 2007.

PORCILE, G.; CURADO, M.. Rigidez na balança comercial e movimentos de capital: uma abordagem estruturalista. Revista Brasileira de Economia, v.56, n.3, p.483-495, 2002.

PRAÇA, E. R.. Distribuição de Gás Natural no Brasil: Um Enfoque Crítico e de Minimização de Custos. Dissertação (Mestrado em Engenharia de Transportes) - Universidade Federal do Ceará, Fortaleza, 2003.

PREBISCH, R.. Notas sobre el intercambio desde el punto de vista periférico. Revista de la CEPAL, n.28, p.195-206, 1986.

RODRIGUES, M. G.; GUERRA, S. M. G.. Strategy of the gaseous fuels in Brazil for the century XXI. In: THE NINTH INTERNATIONAL GAS RESEARCH CONFERENCE, 9. Proceedings. 2004.

SANTOS, E. M.. Gás natural: a construção de uma nova civilização. Estudos Avançados, São Paulo, v.21, n.59, p.67-90, 2007.

ZORATTO, L.. A Geração Térmica a Gás e os Impactos na Balança Comercial. Petróleo \& Gás Brasil, v.3, n.11. p.11-13, 2002. 